\title{
Brentuximab Vedotin Monotherapy and Combined with Low Dose Donor Lymphocyte Infusion to Control Minimal Residual Disease and Sustain Clinical Remission in a Child with Relapsed Anaplastic Large Cell Lymphoma
}

\author{
Alina S. Fedorova1*, Maria V. Stegantseva², Nina V. Minakovskaya ${ }^{3}$, Olga V. Aleinikova1 \\ ${ }^{1}$ Clinical Research Department, Belarusian Research Center for Pediatric Oncology, Hematology and Immunology, Minsk Region, \\ Belarus \\ ${ }^{2}$ Laboratory of Genetic Biotechnology, Belarusian Research Center for Pediatric Oncology, Hematology and Immunology, Minsk \\ Region, Belarus \\ ${ }^{3}$ Department of Bone Marrow Transplantation, Belarusian Research Center for Pediatric Oncology, Hematology and \\ Immunology, Minsk Region, Belarus \\ Email: *alina_fedorova@list.ru
}

How to cite this paper: Fedorova, A.S., Stegantseva, M.V., Minakovskaya, N.V. and Aleinikova, O.V. (2017) Brentuximab Vedotin Monotherapy and Combined with Low Dose Donor Lymphocyte Infusion to Control Minimal Residual Disease and Sustain Clinical Remission in a Child with Relapsed Anaplastic Large Cell Lymphoma. Journal of Cancer Therapy, 8, 683-690. https://doi.org/10.4236/jct.2017.88059

Received: April 14, 2017

Accepted: July 25, 2017

Published: July 28, 2017

Copyright (c) 2017 by authors and Scientific Research Publishing Inc. This work is licensed under the Creative Commons Attribution International License (CC BY 4.0).

http://creativecommons.org/licenses/by/4.0/

\begin{abstract}
Minimal residual disease (MRD) appears to have a strong negative predictive value for disease recurrence in children with anaplastic large cell lymphoma (ALCL). Brentuximab vedotin (BV) can be a therapeutic option for MRDpositive patients to achieve molecular remission and to decrease risk of subsequent relapse. We here report a 4-year-old child with ALCL progression during relapse treatment who received $\mathrm{BV}$ as a bridging therapy before haploidentical hematopoietic stem-cell transplantation, and as a maintenance therapy post-transplant alone or combined with simultaneous low dose donor-lymphocyte infusions. MRD monitoring showed a complete molecular response and reflected both $\mathrm{BV}$ efficiency and graft-versus-lymphoma effect.
\end{abstract}

\section{Keywords}

Anaplastic Large Cell Lymphoma, Relapse, Brentuximab Vedotin, Donor Lymphocyte Infusion, Minimal Residual Disease

\section{Introduction}

Despite the high remission rate in childhood anaplastic large cell lymphoma (ALCL) achievable through various conventional chemotherapy treatments, disease recurrence occurs in approximately one third of patients, without signif- 
icant progress over the last decade [1] [2] [3]. Nucleophosmin-anaplastic lymphoma kinase (NPM1-ALK) expressing cells can be detected in peripheral blood in around half of children with ALK-positive ALCL and are a useful tool for chemotherapy response assessment [4]. Minimal residual disease (MRD) appears to have a strong negative predictive value for disease recurrence in children with ALCL [5].

The majority of relapsed patients are required to undergo allogeneic hematopoietic stem-cell transplantation (alloHSCT). Low relapse rate after alloHSCT, as well as effective donor-lymphocyte infusions (DLI) provides evidence for a graftversus-lymphoma (GvL) effect [6] [7]. Incomplete immune reconstitution in the early post-alloHSCT phase, especially after haploidentical transplantation, leads to an increased risk of subsequent relapse. One of the new strategies to prevent relapse after alloHSCT is the target therapy. Brentuximab vedotin (BV), which is an antibody-drug conjugate that targets $\mathrm{CD} 30$, demonstrated sustained responses in patients with recurrent ALCL and had a very moderate adverse-effect profile [8]. BV has been suggested both as a bridge to alloHSCT and as a posttransplantation maintenance therapy, including combination with DLI [9] [10] [11]. The data of using BV in pediatric patients is very limited but encouraging [12] [13] [14].

Here is a report of a child with ALCL progression during relapse treatment who received BV before and after T-cell receptor (TCR)- $\alpha \beta$-depleted haploidentical HSCT, alone or combined with simultaneous DLI. MRD monitoring showed a complete molecular response and reflected both BV efficiency and GvL effect.

\section{Case Report}

A 4-year-old female presented with high fever, right inguinal swelling, traces of blood in stool and enlarged right leg due to lymphostasis. Computerized tomography (CT) and magnetic resonance imaging demonstrated lymphadenopathy in her inguinal, iliac and para-aortic nodes bilaterally, as well as involvement of pelvic soft tissues (Figure 1). An inguinal node biopsy revealed ALCL, common type, CD30+, ALK+, with $\mathrm{t}(2 ; 5)(\mathrm{p} 23 ; \mathrm{q} 35)$. Cerebrospinal fluid did not show presence of lymphoma cells. Bone marrow was negative for CD30 and ALK expressing cells. But $N P M 1 / A L K$ by TaqMan-based quantitative real-time polymerase chain reaction (RQ-PCR) was positive either in bone marrow or in peripheral blood in a quantity of 7 and 140 copies NPM1/ALK per 10,000 copies of ABL (normalized copies numbers - NCNs), respectively (Figure 2). She started her treatment according to the ALCL99 regimen [1]. As the patient remained MRD-positive after prephase $(12 \mathrm{NCNs})$, the treatment was intensified after the $1^{\text {st }}$ inductive course, and she received 5 cycles with high dose methotrexate/cytarabin and L-asparaginase, designed for patients with high risk acute lymphoblastic leukemia [15]. She responded well and complete remission after the $2^{\text {nd }}$ chemotherapy course was achieved. She became MRD-negative before the $2^{\text {nd }}$ course and remained negative during the subsequent treatment. Two months after the therapy RQ-PCR showed a high positive $N P M 1 / A L K$-level in blood, 

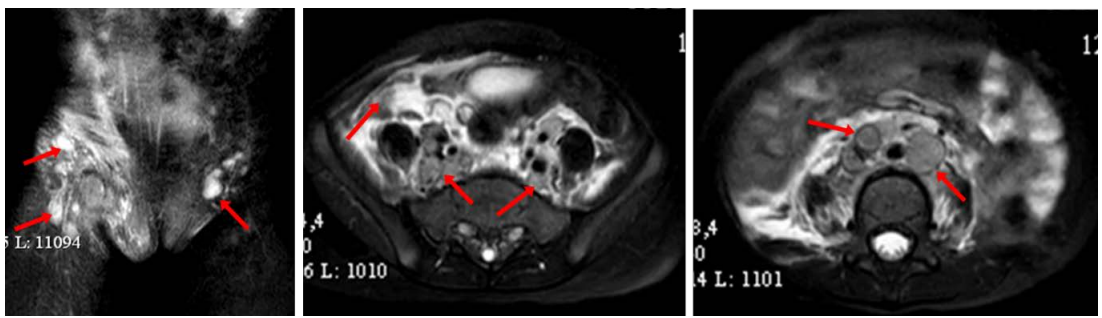

Figure 1. Magnetic resonance imaging demonstrates enlarged inguinal, iliac, para-aortic lymph nodes and involved pelvic soft tissues (denoted by red arrows) at diagnosis.

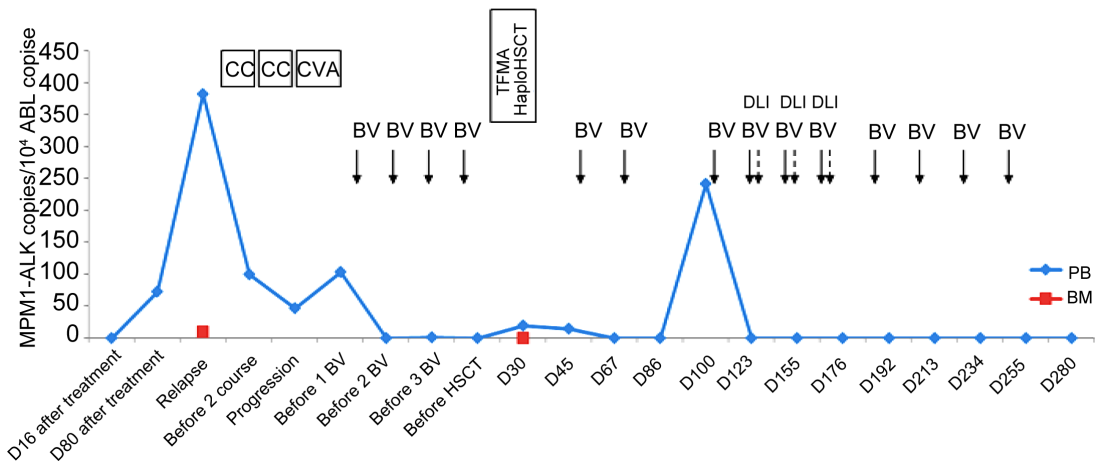

Figure 2. Detection of NPM1-ALK in peripheral blood and bone marrow measured by means of RQ-PCR, and treatment overview after relapse diagnosis in patient with ALCL. $\mathrm{BV}$, brentuximab vedotin; DLI, donor-lymphocyte infusion; $\mathrm{PB}$, peripheral blood; BM, bone marrow; TFMA, a conditioning regimen of treosulfan $\left(42 \mathrm{~g} / \mathrm{m}^{2}\right)$, fludarabine $(150$ $\left.\mathrm{mg} / \mathrm{m}^{2}\right)$, melfalan $\left(140 \mathrm{mg} / \mathrm{m}^{2}\right)$, rabbit anti-thymocyte globuline $(7.5 \mathrm{mg} / \mathrm{kg})$; CC, a chemotherapy course of dexamethasone, vinblastine, cytarabine, etoposide, and intrathecal triplet; CVA, a chemotherapy course of lomustine, vinblastine, cytarabine.

and just one week later she again presented with fevers and left axillary multiple lymph nodes enlargement. Early relapse of ALCL was confirmed by biopsy. In spite of lymphoma cells were not present in bone marrow smears, both bone marrow and peripheral blood were strongly positive for NPM1/ALK (10 and $383 \mathrm{NCN}$, respectively).

A second-line treatment was performed with ALCL relapse 2004 protocol [6]. Clinical response was observed after the $1^{\text {st }}$ cycle. But after the $2^{\text {nd }}$ cycle, chest CT revealed mixed dynamics in a size of lymph nodes involved and appearance of loci in both lungs, while $N P M 1 / A L K$-level in blood remained high (Figure 3). ALCL progression was diagnosed. The break between $2^{\text {nd }}$ and $3^{\text {rd }}$ courses (from start to start) was extended up to 30 days because of chickenpox. After the $3^{\text {d }}$ chemotherapy course, ${ }^{18} \mathrm{~F}$-fluorodeoxyglucose positron emission tomography (PET)/CT revealed stable disease, with the maximum standard uptake values (SUV max) 0.9 in lymph nodes. There was no evidence of CD30+ ALK+ cells in residual tumor obtained in second look biopsy of axillary lymph node. Due to absence of matched donor and persistence of $N P M 1 / A L K$ positivity (103NCNs), monotherapy with BV $1.8 \mathrm{mg} / \mathrm{kg}$ every 21 days was initiated as a bridge to alloHSCT. Informed consent for treatment with BV was obtained from parents. Patient received 4 doses of $\mathrm{BV}$ and tolerated well. NPMI/ALK positivity decreased rapidly and MRD returned to negative after the $1^{\text {st }} \mathrm{BV}$. Twelve days after 


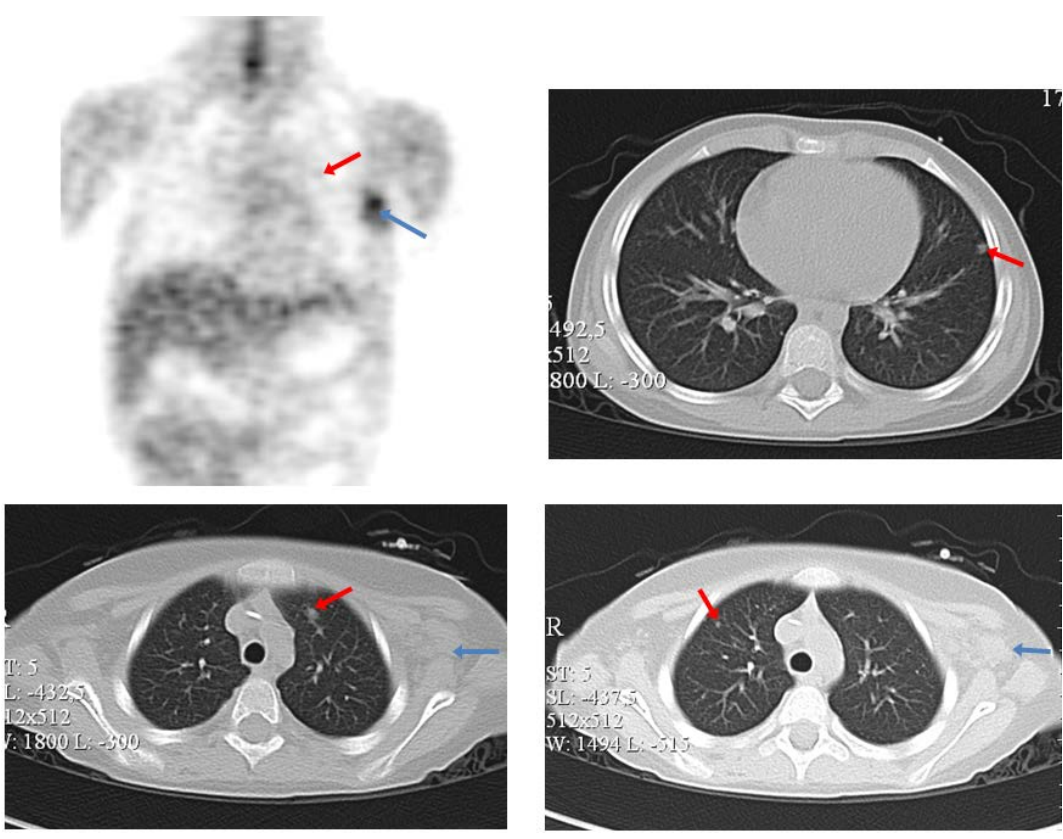

Figure 3. Positron emission tomography/computerized tomography at progression during relapse treatment reveals loci in both lungs (denoted by red arrows) without uptake, and residual tumor at left axillary area (denoted by red arrows) with SUV of 0.9 .

the $4^{\text {th }}$ dose of BV TCR-a $\beta$-depleted haploidentical HSCT from her father was performed (Figure 2). A myeloablative conditioning regimen of treosulfan, fludarabine, melfalan, and rabbit antithymocyte globulin was administered. The donor had KIR-receptors to C1 ligand (KIR2DL2/KIR2DL3), whereas the patient had C2 and Bw4KIR-ligands. The patient achieved neutrophil and platelet engraftment on days 16 and 11, respectively. She showed $100 \%$ donor chimerism on day 30 (STR-PCR, FISH). Immunosuppressive therapy was weaned to day 30 . Her alloHSCT was complicated by cytomegalovirus infection. There were no signs of graft versus host disease (GvHD). RQ-PCR testing on day 30 showed NPM-ALK negativity in bone marrow, but 20NCNs NPM1-ALK in peripheral blood. Considering reappeared MRD, BV was administered at the dose of 1.2 $\mathrm{mg} / \mathrm{kg}$ every 3 weeks from the day 50 (Figure 2). Complete but very short-term molecular response was obtained, and rapid molecular relapse occurred after the $3^{\mathrm{d}} \mathrm{BV}$ infusion (241NCNs NPM1-ALK on day 100). The absence of GvHD signs, very low level of CD3+cells, and high $N P M 1-A L K$-level were the reasons for DLI administration. The patient received totally 3 DLI every 21 days at the increasing doses $\left(2 \times 10^{5} / \mathrm{kg}, 5 \times 10^{5} / \mathrm{kg}\right.$ and $1 \times 10^{6} / \mathrm{kg}$, respectively). BV was administered on the same days shortly after DLI. Both were tolerated very well. MRD conversed to negative after the $1^{\text {st }}$ cycle of DLI and BV. She developed no clinical signs of GvHD afterwards. A PET/CT scan on day 180 showed that the lung loci have disappeared, SUV max 0.9 again in lymph nodes and negative in lungs. The patient continued to receive BV approximately every 3 weeks until T-cells recovery on day 255. Totally the patient received 14 doses of BV. The only side effects were moderate anemia and neutropenia. A PET/CT scan on day 280 showed neither evidence of active disease no residual tumor (Figure 4). The patient is 

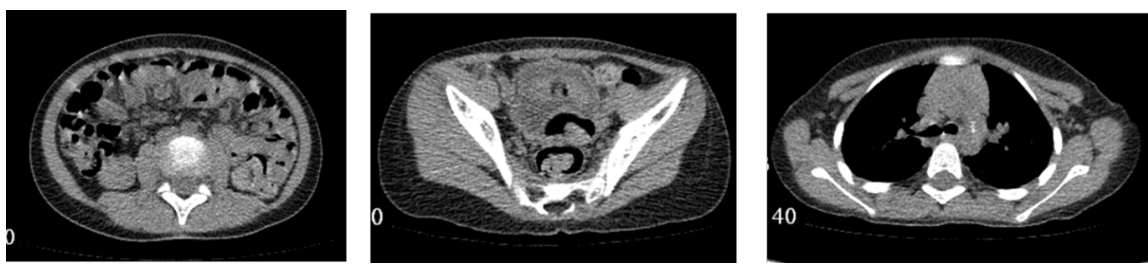

Figure 4. Positron emission tomography/computerized tomography demonstrates complete clinical and metabolic remission on day 280 after haploidentical hematopoietic stem-cell transplantation.

now 12 months from alloHSCT and 4 months from completion of BV in complete clinical and molecular remission.

\section{Discussion}

A majority of ALK-positive ALCLs express NPM1-ALK fusion gene, which is a suitable target for a minimal disease assessment. As shown previously, high number of circulating lymphoma cells at diagnosis and their slow clearance during inductive treatment multiply risk of ALCL recurrence in children [4] [5]. Our patient had high initial NPM1-ALK-level in blood, remained MRD-positive after cytoreductive prephase, and relapsed shortly after the end of the treatment in spite of therapy intensification. Moreover, we observed very short time interval between molecular relapse detection and first clinical symptoms of lymphoma recurrence. In spite of negative morphology of residual relapsed tumor and its minimal metabolic activity, patient preserved very high NPM1- $A L K$-expression in blood, which reflected the evidence of active ALCL and made soon-to-be lymphoma progression almost inevitable. Therefore, we found it meaningful to perform and correct our patient's treatment considering MRD data as well as PET/ CT and morphological response.

In cases of limited chemosensitivity immunotherapy proves to be the rescue option. The efficiency of BV at the doses from 1.2 to $1.8 \mathrm{mg} / \mathrm{kg}$ in heavily pretreated children with ALCL was demonstrated in case reports and a small series of patients, with encouraging results [12] [14]. In our case we used BV as a monotherapy before alloHSCT and observed rapid NPM1-ALK-expressing cells clearance from blood. As our patient was highly likely to relapse into early posttransplantation, before any graft-versus-tumor effect appeared, BV was administered to prevent an early post-transplantation relapse. Retreatment with BV after alloHSCT demonstrated preserved sensitivity to BV and complete but very short-term molecular response, as rapid molecular relapse occurred after the third BV infusion. As it was previously published, retreatment with BV can induce repeated complete remission in relapsed systemic ALCL when considering combining BV with other therapeutic options [16]. Lower dose of BV $(1 \mathrm{mg} / \mathrm{kg})$ also showed its efficiency in a young child treatment with refractory ALCL, minimizing toxic effects [13]. Our patient received BV at a dose of $1.8 \mathrm{mg} / \mathrm{kg}$ before alloHSCT, which was allowed to perform transplantation during molecular remission, and at a dose of $1.2 \mathrm{mg} / \mathrm{kg}$ after alloHSCT, which was adequate to induce molecular and sustain clinical response. 
AlloHSCT has curative potential as a result of the underlying GvL effect, even in patients without complete clinical or molecular response. But haploidentical HSCT implies T-lymphocyte depletion, which postpones GvL manifestation, and increases the risk of an early post-alloHSCT relapse. Combined administration of BV and DLI leads to synergistic anti-tumor effect, and at the same time decreases risk and severity of GvHD due to immunomodulating effect of BV [7] [11]. DLI can result in potentially life-threatening GvHD, while administered to specifically induce or enhance CvL efficacy. We administered very moderate doses of CD3+cells, much lower, than previously reported. And an obvious CvL effect developed after the first DLI of only $2 \times 10^{5} / \mathrm{kg}$ and BV, resulted in rapid MRD negativity. It shows that even low doses of DLI can induct CvL effect. After 3 DLI doses, there were no clinical signs of GvHD. The girl had a good quality of life during the treatment and attended the hospital only for a therapeutic infusion. We didn't find another report of combined BV with DLI post-transplant treatment in children with ALCL.

The patient described here, failed 2 chemotherapy regimens. Administration of BV before and post alloHSCT resulted in a complete molecular response, whilst toxicity was minimal. Post-transplant efficacy should not be attributed to $\mathrm{BV}$ alone but rather to the combination of BV with low doses of DLI. MRD monitoring seems to be useful tool in management of children with NPM1$A L K$-positive recurrent ALCL.

\section{Conflict of Interest}

The authors declare no conflict of interest.

\section{References}

[1] Brugières, L., Le Deley, M.C., Rosolen, A., Williams, D., Horibe, K., Wrobel, G., Mann, G., Zsiros, J., Uyttebroeck, A., Marky, I., Lamant, L. and Reiter, A. (2009) Impact of the Methotrexate Administration Dose on the Need for Intrathecal Treatment in Children and Adolescents with Anaplastic Large-Cell Lymphoma: Results of a Randomized Trial of the EICNHL Group. Journal of Clinical Oncology, 27, 897-903. https://doi.org/10.1200/JCO.2008.18.1487

[2] Lowe, E.J., Sposto, R., Perkins, S.L., Gross, T.G., Finlay, J., Zwick, D., Abromowitch, M. and Children's Group Study 5941 (2009) Intensive Chemotherapy for Systemic Anaplastic Large Cell Lymphoma of Children and Adolescents: Final Results of Children's Cancer Group Study 5941. Pediatr Blood Cancer, 52, 335-339. https://doi.org/10.1002/pbc.21817

[3] Rosolen, A., Pillon, M., Garaventa, A., Burnelli, R., d'Amore, E.S., Giuliano, M., Comis, M., Cesaro, S., Tettoni, K., Moleti, M.L., Tamaro, P., Visintin, G. and Zanesco, L. (2005) Anaplastic Large Cell Lymphoma Treated with a Leukemia-Like Therapy: Report of the Italian Association of Pediatric Hematology and Oncology (AIEOP) LNH-92 Protocol. Cancer, 104, 2133-2140. https://doi.org/10.1002/cncr.21438

[4] Damm-Welk, C., Busch, K., Burkhardt, B., Schieferstein, J., Viehmann, S., Oschlies, I., Klapper, W., Zimmermann, M., Harbott, J., Reiter, A. and Woessmann, W. (2007) Prognostic Significance of Circulating Tumor Cells in Bone Marrow or Peripheral Blood as Detected by Qualitative and Quantitative PCR in Pediatric 
NPM-ALK-Positive Anaplastic Large Cell Lymphoma. Blood, 110, 670-677. https://doi.org/10.1182/blood-2007-02-066852

[5] Damm-Welk, C., Mussolin, L., Zimmermann, M., Pillon, M., Klapper, W., Oschlies, I., d'Amore, E.S., Reiter, A., Woessmann, W. and Rosolen, A. (2014) Early Assessment of Minimal Residual Disease Identifies Patients at Very High Relapse Risk in NPM-ALK-Positive Anaplastic Large-Cell Lymphoma. Blood, 123, 334-337. https://doi.org/10.1182/blood-2013-09-526202

[6] Woessmann, W., Zimmermann, M., Lenhard, M., Burkhardt, B., Rossig, C., Kremens, B., Lang, P., Attarbaschi, A., Mann, G., Oschlies, I., Klapper, W. and Reiter, A. (2011) Relapsed or Refractory Anaplastic Large-Cell Lymphoma in Children and Adolescents after Berlin-Frankfurt-Muenster (BFM)-Type First-Line Therapy: A BFM-Group Study. Journal of Clinical Oncology, 29, 3065-3071.

https://doi.org/10.1200/JCO.2011.34.8417

[7] Theurich, S., Malcher, J., Wennhold, K., Shimabukuro-Vornhagen, A., Chemnitz, J., Holtick, U., Krause, A., Kobe, C., Kahraman, D., Engert, A., Scheid, C., Chakupurakal, G., Hallek, M. and von Bergwelt-Baildon, M. (2013) Brentuximab Vedotin Combined with Donor Lymphocyte Infusions for Early Relapse of Hodgkin Lymphoma after Allogeneic Stem-Cell Transplantation Induces Tumor-Specific Immunity and Sustained Clinical Remission. Journal of Clinical Oncology, 31, e59-63. https://doi.org/10.1200/JCO.2012.43.6832

[8] Pro, B., Advani, R., Brice, P., Bartlett, N.L., Rosenblatt, J.D., Illidge, T., Matous, J., Ramchandren, R., Fanale, M., Connors, J.M., Yang, Y., Sievers, E.L., Kennedy, D.A. and Shustov, A. (2012) Brentuximab Vedotin (SGN-35) in Patients with Relapsed or Refractory Systemic Anaplastic Large-Cell Lymphoma: Results of Phase II Study. Journal of Clinical Oncology, 30, 2190-2196.

https://doi.org/10.1200/JCO.2011.38.0402

[9] Ordemann, R., Stöhlmacher, J., Beuthien-Baumann, B., Platzek, I., van den Hoff, J., Kroschinsky, F., Platzbecker, U., Zietz, C., Bornhäuser, M. and Ehninger, G. (2013) Use of Targeted Therapy for Refractory ALK-Positive Anaplastic Large-Cell Lymphoma as a Bridging Strategy Prior to Allogeneic Transplantation. Annals of Hematology, 92, 125-127. https://doi.org/10.1007/s00277-012-1524-0

[10] Illidge, T., Bouabdallah, R., Chen, R., Gopal, A.K., Moskowitz, C.H., Ramchandren, R., Shustov, A.R., Tilly, H., Trippett, T.M., Gibb, A., Grove, L.E. and Advani, R. (2015) Allogeneic Transplant Following Brentuximab Vedotin in Patients with Relapsed or Refractory Hodgkin Lymphoma and Systemic Anaplastic Large-Cell Lymphoma. Leuk Lymphoma, 56, 703-710. https://doi.org/10.3109/10428194.2014.930852

[11] Tsirigotis, P., Danylesko, I., Gkirkas, K., Shem-Tov, N., Yerushalmi, R., Stamouli, M., Avigdor, A., Spyridonidis, A., Gauthier, J., Goldstein, G., Apostolidis, J., Mohty, M., Shimoni, A. and Nagler, A. (2016) Brentuximab Vedotin in Combination with or without Donor Lymphocyte Infusion for Patients with Hodgkin Lymphoma after Allogeneic Stem-Cell Transplantation. Bone Marrow Transplant, 51, 1313-1317. https://doi.org/10.1038/bmt.2016.129

[12] Koh, K.N., Im, H.J., Suh, J.K., Lee, S.W., Choi, E.S. and Seo, J.J. (2015) Successful Use of Brentuximab Vedotin for Refractory Anaplastic Large Cell Lymphoma as a Bridging Therapy to Haploidentical Stem Cell Transplantation and Maintenance Therapy Post-Transplantation. Pediatric Blood \& Cancer, 62, 1063-1065. https://doi.org/10.1002/pbc.25351

[13] Mikles, B., Levine, J., Gindin, T., Bhagat, G. and Satwani, P. (2014) Brentuximab Vedotin (SGN-35) in a 3-Year-Old Child with Relapsed Systemic Anaplastic Large Cell Lymphoma. Journal of Pediatric Hematology/ Oncology, 36, e85-87. 
https://doi.org/10.1097/MPH.0b013e31828aff2c

[14] Myakova, N.V., Evstratov, D.A., Abramov, D.S., Konovalov, D.M., Pshonkin, A.V. and Litvinov, D.V. (2016) Brentuximab Vedotin in Children and Adolescents with Hodgkin's Lymphoma and Anaplastic Large-Cell Lymphoma-Literature Review and Own Experience. Oncohematology, 11, 8-13. https://doi.org/10.17650/1818-8346-2016-11-1-8-13

[15] Stary, J., Zimmermann, M., Campbell, M., Castillo, L., Dibar, E., Donska, S., Gonzalez, A., Izraeli, S., Janic, D., Jazbec, J., Konja, J., Kaiserova, E., Kowalczyk, J., Kovacs, G., Li, C.K., Magyarosy, E., Popa, A., Stark, B., Jabali, Y., Trka, J., Hrusak, O., Riehm, H., Masera, G. and Schrappe, M. (2014) Intensive Chemotherapy for Childhood Acute Lymphoblastic Leukemia: Results of the Randomized Intercontinental Trial ALL IC-BFM 2002. Journal of Clinical Oncology, 32, 174-184. https://doi.org/10.1200/JCO.2013.48.6522

[16] Bartlett, N.L., Chen, R., Fanale, M.A., Brice, P., Gopal, A., Smith, S.E., Advani, R., Matous, J.V., Ramchandren, R., Rosenblatt, J.D., Huebner, D., Levine, P., Grove, L. and Forero-Torres, A. (2014) Retreatment with Brentuximab Vedotin in Patients with CD30-Positive Hematologic Malignancies. Journal of Hematology \& Oncolo$g y, 7,24$.

http://www.jhoonline.org/content/7/1/24 https://doi.org/10.1186/1756-8722-7-24

Submit or recommend next manuscript to SCIRP and we will provide best service for you:

Accepting pre-submission inquiries through Email, Facebook, LinkedIn, Twitter, etc. A wide selection of journals (inclusive of 9 subjects, more than 200 journals)

Providing 24-hour high-quality service

User-friendly online submission system

Fair and swift peer-review system

Efficient typesetting and proofreading procedure

Display of the result of downloads and visits, as well as the number of cited articles Maximum dissemination of your research work

Submit your manuscript at: http://papersubmission.scirp.org/

Orcontact jct@scirp.org 